\title{
Factors of corruption on the firm level
}

\author{
Murat Bakeev \\ Faculty of Economic Sciences \\ HSE \\ Moscow, Russia \\ mbbakeev@gmail.com \\ Nikolaeva Anna \\ Department of Economics and Management \\ KNRTU-KAI \\ Kazan, Russia \\ annanikolaeva@bk.ru
}

\author{
Safargaliev Mansur \\ Department of Economics and Management \\ KNRTU-KAI \\ Kazan, Russia \\ safargaliev@list.ru \\ Garifullin Ruslan \\ Department of Economics and Management \\ KNRTU-KAI \\ Kazan, Russia \\ deeltaar@mail.ru
}

\author{
Nefedova Julia \\ Department of Economics and Management \\ KNRTU-KAI \\ Kazan, Russia \\ niko_julia@mail.ru
}

\begin{abstract}
What makes managers of firms to pay bribes? What factors influence it? We analyze factors affecting managerial decisions to pay bribes in order to understand why some firms pay bribes, while others do not. The conceptual framework of our study is based on the analysis of several approaches presented in the previous research papers. We combine those approaches, dividing corruption into two different types and building separate models for each of these types. After that, we test those models along with an overall corruption model on data from "EBRDWorld bank Business Environment and Enterprise Performance Survey" (BEEPS) to decide if the separation is necessary. We find that treating corruption as a heterogeneous phenomenon is not preferable, but further research of the problem is needed, because the models built are rather insufficient and require an adjustment.
\end{abstract}

Keywords-corruption; bribery; firm

\section{INTRODUCTION}

There is an academic consensus that corruption is more often in developing countries, and it is costly for them in terms of economic growth [10]. Corruption is an important environmental factor that destabilizes the production system and hinders economic development [1]. That is why the international policy community and civil society in those countries are interested in reduction of the corruption level. In its turn, this aim is achievable only if we have a proper understanding of factors of corruption.

There are various ways to analyze these factors. In this paper, we examine the "supply side" of corruption, factors influencing firms' decisions to make illicit payments. While corruption includes a huge variety of activities such as, for example, theft of government resources by public officials [10, p. 480], here we focus only on bribery.

Usually, bribes are treated as homogeneous phenomena. The only distinction provided is a difference between "lowerlevel" administrative corruption and "upper-level" political corruption [9, pp. 10-11]. In this article, we use an idea of separating bribery on "grease-the-wheels" and "sand-thewheels" payments in dependence of their influence on business activity, following Demenet, Ho and Morcillo [3]. Since we assume those types of payments are of different economic nature, we provide different models for them, addressing to previous works on the discussed issue. Our main research question is whether this separation and usage of the "composite" model is better than considering bribery as a homogeneous phenomenon. Is there any crucial difference between factors of certain bribery practices?

\section{CONCEPTUAL FRAMEWORK}

Economic studies of corruption can be divided into three major groups by the approaches used in those researches.

The eldest approach is connected with the principal-agent model of corruption and can be represented by studies of Becker and Stigler [2], Rose-Ackerman [13], Klitgaard [8]. It focuses on the problem of motivating a bureaucrat not to take bribes and mostly analyzes relationships between politicians and local officials.

The most remarkable study of the second approach is "Corruption" by Shleifer and Vishny [14]. It examines the ways corruption networks are organized, provides the models for different types of "corruption" market: the monopoly 
corruption with single corrupt dictator, the monopolistic competition with several independent officials "producing" complementary government goods and competitive "corruption" market.

The third approach focuses on the "supply-side" of corruption and is represented by a bunch of modern empirical studies. The authors of those research works analyze the relationships between certain firms' characteristics and their corruptness, between the corruptness and firm performance.

This research paper continues the work done in the studies connected to the third approach. We try to provide theoretical framework for the studied case combining the models and approaches used in the other research works.

The first article we address to in our paper is "Firm-level corruption: Unravelling sand from grease" by Demenet et al. [3]. It examines the relationship between bribe payments and firm performance, while our goal is in comprehending the firmlevel factors of corruptness. However, we are interested in using certain methodological approach of that article, which is the heterogeneous nature of bribe payment hypothesis.

The authors of the study claim that in fact there are essentially two types of bribe payments. In the first type, firms have incentives to pay bribes in order to obtain benefits "they would not be able to get without bribe payments" [3, p. 2]. Thus, bribe payments to gain government contracts, to evade taxes and customs, to affect policymaking should fit this type of corruption, called "grease-the-wheel" bribery. The second type is called "sand-the-wheel"; in the case of it firms "pay to obtain something that they would get by default as soon as they fulfilled certain legal requirements" [3, p. 2]. The second type is related to bribe payments to get public services, licenses and permits.

Using the hypothesis, we treat the two considered types of bribe payments separately. In our view, the previous studies missed the point in some way, trying to provide a single model for all bribe payments. Probably, a more correct way is to build separate models for different types of corruption.

Then we find the studies that, we believe, are successful in building adequate models for each considered type of bribe payments. Firstly, let us move to "sand" corruption. In our opinion, the effective approach explaining association between firms' features and "sand" bribe payments can be found in Svensson [15].

He assumes that the probability and amount of bribe payments depends on two factors: officials' opportunity to extract bribes and firms' ability to resist. Svensson suggests two hypotheses to explain each of the factors. The first is "control rights hypothesis" and it claims that opportunity to extract bribes depends on amount of "control rights" which bureaucrats have. These control rights, Svensson says, "stem from the existing regulatory system and the discretion public officials have in implementing, executing, and enforcing rules and benefits that affect firms, such as business regulations, licensing requirements, permissions, exemptions, and public-goods provision" $[15$, p. 210$]$. In fact, we can interpret them as officials' opportunity to influence on firms' business decisions.
The second factor is explained using the "bargaining hypothesis". Svensson assumes that "the official will try to extort as high a bribe as possible, subject to the constraints that $<\ldots>$ the firm might exit" [15, pp. 210-211]. Therefore, a magnitude of bribe payment is influenced by bargaining positions of firms and bureaucrats. Higher the ability of firm to pay the bribe, higher the bribe is paid; lower the cost of not paying (leaving the business), lower the bribe is paid.

Svensson uses future profits to measure the firm's ability to pay and alternative return on the firm's capital stock to measure their refusal power [15, p. 211]. He shows that this return depends on a magnitude of the sunk component in firm's capital and, thus, firm's choice of technology determines the cost of leaving a business.

In addition, he presumes that firms' size is positively associated with probability of bribe payments, because larger firms are more "visible" to demands from corrupt officials [15, p. 214]. This presumption is consistent with empirical results of some studies, such as "Firm-level corruption: Unravelling sand from grease" mentioned above [13]. However, some authors, such as Paunov [11], show that "sand" corruption (particularly the bribe payments to get operating licenses) affects only small firms. Moreover, there is a serious argument in literature that large enterprises can protect themselves from corruption more easily [16]. There are following reasons for that: large enterprises' size makes them "more immune from the extortion of petty bureaucrats", they can rely on "individuals skilled at going through jungle of opaque regulations and laws", and they can use "political power to influence relevant individuals in public administration" [16, p. 28].

Thus, the influence of firm size on the level of corruption is rather contradictory and, probably, it differs for groups of smaller and larger firms. In can be mentioned that the "visibility" hypothesis was confirmed in studies mostly using data consisted of information on small and medium enterprises (SMEs). Thereby, our hypothesis suggests that the visibility factor works for SMEs, but for large firms the immunity factor has impact that is more significant.

In our opinion, Svensson's approach corresponds to "sand" type of corruption, because in his model firms do not have any incentives to bribe. It is officials who only force them with varying degrees of success. However, in the cases of "grease" corruption (bribe payments to get government contracts, to evade taxes, customs) firms play "active role", it is up to them - choose to pay a bribe or not.

Therefore, we need an alternative model for "grease" corruption. In our view, such model can be found in Jeong and Weiner [7].

These authors focus on incentives of a firm management when deciding to pay a bribe. Particularly they work with bribes in order to get government contracts - "grease" corruption in our classification. They presume that three factors have major impact on management's behavior. The first is contract rent: the surplus firm gets after paying a bribe. In this logic, increasing contract rent increases incentives to bribe officials. The second factor is ownership structure. Jeong and Weiner explain the way ownership structure affects "grease" bribe payments using 
principal-agent framework. They suggest that owners-manages in private companies are interested in profits most, therefore, their incentives to bribe is the highest. Managers in publicly held firms "bear the risk and consequences of detection and punishment, yet may not benefit from the outcome of bribery decisions, depending on their ownership in the firm" [7, p. 1368]. Thereby, they are expected to bribe less. Finally, benefits of managers in partially and fully state-owned firms from bribery decisions are rather very small, thus managers in such firms are expected not to bribe in most of the cases.

The third factor considered by Jeong and Weiner is homecountry institutional environment, which obviously influences managerial decisions "through likelihood and consequences of detection" [7, p. 1376]. Of course, home-country institutions affect both considered types of corruption. However, in this paper we focus on firms' features and do not aim to analyze government institutions.

Speaking of firm size, in our view, it is significant in the case of "grease" corruption and has a positive association with "grease" payments. There is an evidence that officials are more likely to deal with larger firms in Paunov [11, p. 220]. Moreover, some forms of rent-seeking activities such as political corruption are affordable for larger enterprises only.

\section{DATA}

Based on the conceptual framework presented above, we build separate models for each type of corruption and test them on data from "EBRD-World bank Business Environment and Enterprise Performance Survey (BEEPS)" [4]. In particular, we work with cross-sectional data from the fifth round of the BEEPS in 2012-2016 that covered 16,566 enterprises in 32 countries of Eastern Europe and Central Asia. BEEPS is "a firm-level survey of a representative sample of an economy's private sector whose objective is to gain an understanding of firms' perception of the environment in which they operate" [5].

The survey covers a wide range of business environment topics. There are questions about finance, economic performance, competition, infrastructure etc. [5]. The questionnaire also includes questions about corruption, based on which we construct the empirical part of our study. It is especially useful that the survey's questions enable to measure the level of "sand" and "grease" corruption separately.

We use the data on necessity of bribe payments in 5 possible cases (getting access to electricity, water, construction permits, operating and import licenses) to measure the "sand" corruption by constructing an aggregate indicator for each surveyed firm.

The information about the bribery in order to evade taxes and customs, to influence government decisions in courts, parliaments, central and local administrations (6 cases) is used to measure "grease" bribe payments by constructing another aggregate indicator.

The overall corruption indicator, constructed for further comparison with the separate models, reflects both of the bribery cases, which we described above. All of the indicators are normalized to a single scale, taking values from zero to one.
TABLE I. DESCIPTIVE STATISTICS (CORRUPTION INDICATORS)

\begin{tabular}{|l|l|l|}
\hline \multicolumn{1}{|c|}{ Corruption } & \multicolumn{1}{|c|}{ Mean } & Sid. Dev. \\
\hline Overall & 0.22 & $(0.091)$ \\
\hline "Sand" & 0.17 & $(0.095)$ \\
\hline "Grease" & 0.27 & $(0.129)$ \\
\hline
\end{tabular}

We assume that a part of corruption determinants are homogeneous inside specific industries, hence information about industry affiliation of a firm can be used for our purposes. Additionally, we take the institutional factor into consideration by introducing a country variable.

After cleaning of the data from samples with any of used parameters unknown and removing industries with a very few surveyed firms, we get 3499 observations in 32 countries and 22 industries (table 2). 
TABLE II. NUMBERS OF OBSERVATION IN DIFFERENT COUNTRIES AND INDUSRTIES

\begin{tabular}{|c|c|c|c|}
\hline Country & $\begin{array}{l}\text { Numer } \\
\text { of obs. }\end{array}$ & Industry & $\begin{array}{c}\text { Number } \\
\text { of obs. }\end{array}$ \\
\hline Albania & 31 & Food & 293 \\
\hline Belarus & 82 & Textiles & 82 \\
\hline Georgia & 62 & Garments & 84 \\
\hline Tajikistan & 83 & Wood & 74 \\
\hline Turkey & 296 & Media & 46 \\
\hline Ukraine & 121 & Chemicals & 105 \\
\hline Uzbekistan & 120 & Plastics \& Rubber & 50 \\
\hline Russia & 765 & $\begin{array}{l}\text { Non metallic mineral } \\
\text { products }\end{array}$ & 164 \\
\hline Poland & 53 & Fabricated metal products & 153 \\
\hline Romania & 153 & Machinery and equipment & 96 \\
\hline Serbia & 74 & Electronics & 46 \\
\hline Kazakhstan & 130 & Precision instruments & 39 \\
\hline Moldova & 99 & Furniture & 66 \\
\hline $\begin{array}{l}\text { Bosnia- } \\
\text { Herzegovina }\end{array}$ & 117 & Construction & 385 \\
\hline Azerbaijan & 31 & Services of motor vehicles & 97 \\
\hline $\begin{array}{l}\text { FYR } \\
\text { Macrdonia }\end{array}$ & 137 & Wholesale & 437 \\
\hline Armenia & 90 & Retail & 893 \\
\hline Kyrgyzstan & 107 & Hotel and restaurants & 167 \\
\hline Mongolia & 162 & Transport & 84 \\
\hline Estonia & 59 & $\begin{array}{ll}\text { Supporting } & \text { transport } \\
\text { activities } & \\
\end{array}$ & 63 \\
\hline Kosovo & 65 & $\begin{array}{l}\text { Post } \\
\text { telecommunication }\end{array}$ & 44 \\
\hline Czech Republic & 55 & IT & 31 \\
\hline Hungary & 43 & & \\
\hline Latvia & 32 & & \\
\hline Lithuania & 56 & & \\
\hline $\begin{array}{l}\text { Slovak } \\
\text { Republic }\end{array}$ & 49 & & \\
\hline Slovenia & 86 & & \\
\hline Bulgaria & 46 & & \\
\hline Croatia & 137 & & \\
\hline Montenegro & 28 & & \\
\hline Cyprus & 76 & & \\
\hline Greece & 54 & & \\
\hline $\begin{array}{l}\text { Overall }(32 \\
\text { countries })\end{array}$ & 3499 & Overall (22 industries) & 3499 \\
\hline
\end{tabular}

In the survey, we have only information about employment magnitude, thus it is used to measure firms' size (table 1). We rely on European Commission classification when dividing firms on the groups of SMEs and large companies. According to European Commission, a big firm includes more or is equal to 250 employees, while a small or medium enterprise includes fewer than 250 employees [6].

TABLE III. DESCRIPTIVE STATISTICS (SIZE MEASURED WITH LABOR FORCE)

\begin{tabular}{|l|c|c|c|}
\hline \multicolumn{1}{|c|}{ Labor force } & Obs. & Mean & Std Dev. \\
\hline Overall & 3499 & 92.52 & $(331.56)$ \\
\hline SMEs & 3247 & 38.94 & $(47.6)$ \\
\hline Large & 252 & 782.77 & $(993.61)$ \\
\hline
\end{tabular}

There are plenty of questions about features of a firm's ownership form and structure in the survey. For instance, those are questions about the firm's current legal status, about percentage of a firm owned by state or private individuals, about a share of the largest owner, etc. Based on these data, we provide information about the ownership structure in order to test the "ownership structure hypothesis", using a categorical variable, where the three categories are government and partially government firms, publicly held firms and privately held firms. Sizes of the each category are presented below (table 3).

TABLE IV. NUMBERS OF OBSERVATIONS IN DIFFERENT CATEGORIES OF OWNERSHIP STRUCTURE

\begin{tabular}{|l|c|}
\hline \multicolumn{1}{|c|}{ Ownership Type } & Number of obs. \\
\hline Privately held & 3249 \\
\hline Publicly held & 116 \\
\hline Fully or partially owned by state & 134 \\
\hline
\end{tabular}

\section{METHODOLOGY}

We assume that "sand" corruption is determined by the level of control rights officials have, by future economic profits, by degree of liquidity of firm's capital and firm's size. However, we could not get information about these factors excluding the firm size from the survey. Thus, we decide to assume that the considered factors are more or less homogeneous inside a specific industry, since the laws, costs and technologies used are more or less the same in the specific industries. Thereby, we are able to replace the considered factors with a single industry categorical variable.

The same situation arises in the case of "grease" bribery, since we do not have information about corruption contract rents. Consequently, we are forced to assume that those rents are homogeneous inside specific industry, thus they can be replaced by the industry variable.

We have information about ownership structure of firms from the data, and the same with firms' size. The institutional 
factor is samled using the country variable. Therefore, there are no any other serious assumptions needed to be made.

A method we use to comprehend whether the separation on bribery types is useful is comparing the linear regression models by dint of Akaike info criterion (AIC). We have two separate models for each type of corruption and two possible specifications for a joint "corruption" model. In addition, we control overall adequacy of the models used by checking significance of variables.

Summarizing, the tested models are:

1) Sand $=\alpha+\beta_{1}$ size $+\sum_{i=2}^{22} \beta_{i}$ industry $_{i-1}+$ $\sum_{i=23}^{53} \beta_{i}$ country $y_{i-1}+\varepsilon$

2) Grease $=\alpha+\beta_{1}$ size $+\sum_{i=2}^{22} \beta_{i} *_{i n d u s t r y}+1+$ $\sum_{i=23}^{53} \beta_{i}{ }^{*}$ country $_{i-1}+\sum_{i=54}^{55} \beta_{i}{ }^{*}$ ownership $_{i-1}+\varepsilon$.

3) Corruption $=\alpha+\beta_{1}$ size $+\sum_{i=2}^{22} \beta_{i}$ industry $_{i-1}+$ $\sum_{i=23}^{53} \beta_{i}$ country $_{i-1}+\varepsilon$

4) Corruption $=\alpha+\beta_{1}$ size $+\sum_{i=2}^{22} \beta_{i} *_{\text {industry }}$ in-1 + $\sum_{i=23}^{53} \beta_{i}{ }^{*}$ country $_{i-1}+\sum_{i=54}^{55} \beta_{i}$ ownership $_{i-1}+\varepsilon$.

"Sand" - the normalized aggregate indicator taking values from 0 to 1. Each of the "sand" corruption cases raises it with some equal weight.

"Grease" - the normalized aggregate indicator taking values from 0 to 1 . Each of the "grease" corruption cases raises it with some equal weight.

"Corruption" - the normalized aggregate indicator taking values from 0 to 1 . Each of any cases of corruption raises it with some equal weight.

"Ownership" - the categorical variable representing the ownership structure of a firm. It has three possible values representing the situations when the firm is owned by private indivuals and do not have shares traded in the stock market, when the firm is publicly held and when the firm is fully or partially owned by state.

"Industry" - the categorical variable representing the industry of a firm. Each industry has a specific number (e.g. Retail $=52$ )

"Country" - the categorical variable representing the origin country of a firm. Each country has a specific number (e.g. Albania = 44).

"Size" - a number of workers of a firm. If a firm has an amount of employees less than 250; then it is considered as a SME.

\section{RESULTS AND DISCUSSION}

The analysis of AICs shows that using separate models for the different types of corruption is not preferable. We use the specification of the "corruption" model without an "ownership" variable because of its insignificance revealed. This model has an AIC equal to -7226.698, while the "sand" model has an AIC equal to -6797.864 and the "grease" model has an AIC equal to -4684.447. The joint model's AIC is lower than both AICs of the separate models, thus the result is not hypothesis confirming.

However, a set of discrepancies with the conceptual framework of the paper occurs in the outcomes of the analysis, which prevents us from fully relying on the results.

Firstly, only some of the countries are significant in explaining the "sand", "grease" or "corruption" indicators. The most important, some of the countries that failed in explaining are rather small (e.g. Montenegro), and they surely have homogeneous institutional environment. Probably, some typology of countries based on institutional characteristics is required to make the models more adequate. Another possible way is using a set of institutional variables instead of country variable.

Secondly, the industry variable is rather poor in explanation, which suggests that assumption about identical levels of control rights, capital liquidity, future incomes and contract rents in the one industry is inadequate.

Thirdly, "ownership structure" hypothesis is partially confirmed for the "grease" indicator: we find that publicly held companies are usually less corrupt, while there is no any relationship for government companies. Thus, though incentives' analysis provided in the conceptual framework needs an elaboration, it makes sense. Therefore, following research, comprehending why government companies sometimes make bribe payments, can be useful. It may be the case that deeper analysis of country institutions is also needed in this case.

Finally, the "size" variable is relatively significant only in the "sand" model and has a negative value, which shows that the specific "visibility" factor exists and prevails. This result corresponds to the finding of Rand and Tarp on the data on Vietnamese SMEs [12]. Nevertheless, the "size" becomes insignificant in the case of testing the model on a sample of only large firms. Probably, it can be explained by a fact that small and medium enterprises predominate in our data. Concerning that, further study focusing on large companies is necessary for comprehension of the association between discussed "visibility" and "immunity" factors and supplementary evidence of their specificity and existence.

\section{CONCLUSION}

Using the relevant data on bribery in various countries of Eastern Europe and Central Asia, we examined the determinants of corruption from the supply side and tested necessity of dividing bribery payments into "sand" and "grease" types. The AICs' comparison disproved our hypothesis, showing an absence of any necessity of the separation.

However, the models we use including the overall "corruption" model seem to be insufficient. There are several possible reasons for it aside from inefficiency of theory used. Most likely, the assumption about homogenous control rights, alternative return on capital stock, future incomes and contract rents in the industry is inaccurate. 
Thereby, a further study testing the "sand" model with different variables for control rights, alternative returns on capital and incomes and testing the "grease" model with the variable measuring contract rents should be hold in order to confirm the heterogeneous bribe payment hypothesis.

In addition, we did not take into account local institutions (a regional factor), which can seem crucial, though the example of Montenegro disproves it.

Besides, corruption can be primarily determined by "demand" factors (officials incentives to extract bribes), and "supply" factors can have rather small impact on actual levels of bribery. In fact, perfect research should take fully into account the both sides for a truly versatile vision of the phenomenon of corruption. However, it is rather a complex task to collect the data on the industrial organization of corruption market, to make a deep analysis of design of institutions and then match the acquired information with data on the "supply" factors of corruption. Moreover, necessity of any kind of typology of bribery payments on the "demand" side should be examined on a theoretical level. Our study showed that the separation criterion we used ("sand" or "grease" payments) seems to be pointless, but there are other possible ways of separation on the level of "demand" side, which can be tested using empirical data.

In our opinion, this kind of study, based on comparing the two sides of the corruption market and uniting them into a one framework, can be a possible way of further research of the problem.

\section{References}

[1] B. Bakeev, I. Bakeeva, A. Kornilin, V. Sudnikov, J. Nefedova, "Improving the production procedures on the basis of principles of the organization of production," Bulletin of the Kazan State Technical University, A.N. Tupolev., 2017, vol. 73, no 4, pp. 124-129.
[2] G. S. Becker, G. J. Stigler, "Law enforcement, malfeasance, and compensation of enforcers," The Journal of Legal Studies, 1974, vol. 3, no 1 , pp. 1-18.

[3] A. Demenet, H.-A Ho., S. Morcillo, "Firm-level corruption: Unravelling sand from grease," WIDER Working Paper 2017/123, Helsinki: UNUWIDER, 2017.

[4] EBRD \& World bank, "EBRD-World bank Business Environment and Enterprise Performance Survey (BEEPS). 2012-2016," 2017, Available April 26, 2018, from http://ebrd-beeps.com, 2012-2016.

[5] EBRD \& World bank, “About BEEPS,” 2018, Available April 26, 2018, from http://ebrd-beeps.com/about/.

[6] EU Commission, "Commission staff working document on the implementation of Commission Recommendation of 6 May 2003 concerning the definition of micro, small and medium-sized enterprises," SEC(2009) 1350 final, Brussels: European Comission, 2009.

[7] Y. Jeong, R. J. Weiner, "Who bribes? Evidence from the United Nations' oil- for- food program," Strategic Management Journal, 2012, vol. 33, no 12, pp. 1363-1383.

[8] R. Klitgaard, "Gifts and bribes," Strategy and Choice, United States of America: MIT Press, pp. 419-435, 1991.

[9] S. D. Morris, "Forms of corruption," DICE Report, 2011, vol. 9, no 2, pp. 10-14.

[10] B. A. Olken, R. Pande, "Corruption in developing countries," Annual Review of Economics, 2012, vol. 4, no 1, pp. 479-509.

[11] C. Paunov, "Corruption's asymmetric impacts on firm innovation," Journal of Development Economics, 2016, vol. 118, pp. 216-231.

[12] J. Rand, F. Tarp, "Firm-level corruption in Vietnam," Economic Development and Cultural Change, 2012, vol. 60, no 3, pp. 571-595.

[13] S. Rose-Ackerman, "The economics of corruption," Journal of Public Economics, 1975, vol. 4, no 2, pp. 187-203.

[14] A. Shleifer, R. W. Vishny, "Corruption," The Quarterly Journal of Economics, 1993, vol. 108, no 3, pp. 599-617.

[15] J. Svensson., "Who must pay bribes and how much? Evidence from a cross section of firms," The Quarterly Journal of Economics, 2003, vol. 118, no 1, pp. 207-230.

[16] V. Tanzi, "Corruption around the world: Causes, consequences, scope, and cures," IMF Staff Papers, vol. 45, no 4, pp. 559-594. 